\title{
Implementable Strategy Research of Brake Energy Recovery Based on Dynamic Programming Algorithm for a Parallel Hydraulic Hybrid Bus
}

\author{
Zhong-Liang Zhang Jie Chen \\ School of Mechanical Engineering, Shanghai Jiao Tong University, Shanghai 200240, China
}

\begin{abstract}
The purpose of this paper is to develop an implementable strategy of brake energy recovery for a parallel hydraulic hybrid bus. Based on brake process analysis, a dynamic programming algorithm of brake energy recovery is established. And then an implementable strategy of brake energy recovery is proposed by the constraint variable trajectories analysis of the dynamic programming algorithm in the typical urban bus cycle. The simulation results indicate the brake energy recovery efficiency of the accumulator can reach $60 \%$ in the dynamic programming algorithm. And the hydraulic hybrid system can output braking torque as much as possible. Moreover, the accumulator has almost equal efficiency of brake energy recovery between the implementable strategy and the dynamic programming algorithm. Therefore, the implementable strategy is very effective in improving the efficiency of brake energy recovery. The road tests show the fuel economy of the hydraulic hybrid bus improves by $22.6 \%$ compared with the conventional bus.
\end{abstract}

Keywords: Implementable strategy, brake energy recovery, dynamic programming, parallel hydraulic hybrid bus, shifting schedule, pump/motor displacement.

\section{Introduction}

Much kinetic energy of conventional vehicles is dissipated by frictional brake system in the urban traffic cycle with the characteristic of frequent go-stop pattern. For example, such as London bus cycle, Japan 10-15 bus cycle and New York city cycle, the percentage of the brake energy to the traction energy are $66.6 \%, 48.3 \%$ and $71.1 \%$, respectively ${ }^{[1]}$. However, hybrid vehicles can recover these brake energy and improve energy usage efficiency. For the high power density and the high energy conversion efficiency of hydraulic accumulator, hydraulic hybrid system (HHS) has greater dominance than its electrical counterpart in accelerating vehicles or recovering huge brake energy ${ }^{[2]}$. Therefore, it is particularly suitable for medium or heavy vehicles in heavy traffic and urban area ${ }^{[3]}$.

Many researches have been performed on the influence factors of the brake energy efficiency in the hydraulic hybrid vehicle (HHV). Zhang and Chang ${ }^{[4]}$ studied how different initial braking pressures and volumes of accumulator impact on the efficiency of brake energy recovery and braking performance. Chen and $\mathrm{Vu}^{[5]}$ also analyzed different initial pressures of the hydraulic accumulator and the displacement of the hydraulic pump for their effect on the efficiency of brake energy recovery. However, these studies and analyses are achieved based on a coasting brake process and braking force produced exclusively by an HHS.

$\mathrm{Wu}$ et al. ${ }^{[6]}$ developed an optimal energy management algorithm for improving the fuel economy of the hydraulic hybrid medium truck. Sun et al. ${ }^{[7]}$ proposed a fuzzy torque control strategy for controlling instantaneously the energy

\section{Regular Pape}

Special Issue on Recent Advances on Complex Systems Control, Modelling and Prediction

Manuscript received June 18, 2013; revised December 9, 2013

This work was supported by Shanghai Science and Technology Committee (No. 0904H155100). distribution in a parallel hydraulic hybrid vehicle. Although they proposed an integrated methodology of propulsion and braking to improve the fuel economy in a typical urban cycle, the braking characteristics were not investigated deeply. Moreover, the distribution of braking force and the efficiency of brake energy recovery are hardly considered and optimized. Therefore, it is necessary for an HHV to develop an implementable strategy of brake energy recovery in a typical urban cycle.

In this paper, a new HHS configuration is first introduced. Second, a dynamic programming (DP) algorithm of brake energy recovery is proposed. And the objective function and the constraint conditions are acquired by analyzing the brake process. Third, the simulation results of the gear ratio of torque coupler and the displacement of pump/motor are investigated for acquiring an implementable strategy of brake energy recovery in the maximal brake power cycle. Fourthly, the implementable strategy is validated which can reach almost equal brake energy recovery efficiency of the DP algorithm. Finally, the brake energy recovery efficiency of the accumulator and the fuel economy of the engine are measured in the road tests.

\section{New HHS configuration}

Fig. 1 presents a schematic diagram of a new HHS configuration which consists of a variable hydraulic pump/motor, hydraulic control valves, an accumulator, a pressurized tank, a torque coupler, an HHS controller and associated sensors. The HHS parallels the conventional powertrain and the driven wheels are the rear wheels. The variable hydraulic pump/motor is coupled with the propeller shaft by a torque coupler. The position of the brake pedal is measured by an angular sensor. The zero frictional force is resulted from employing the clearance between the brake 
pedal and plate.

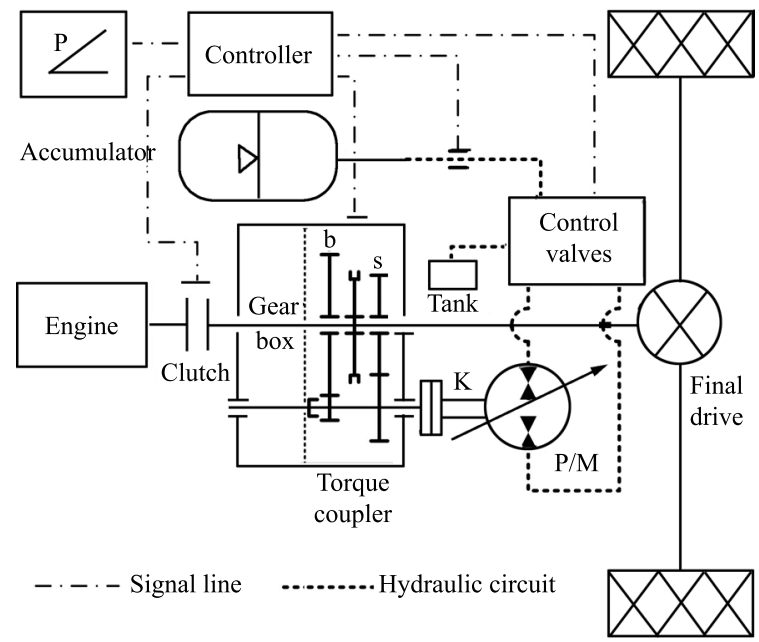

Fig. 1 A schematic diagram of HHS

When a driver depresses the brake pedal, the HHS controller makes the torque coupler keep a proper gear ratio and the hydraulic control valves work with the brake state. And then the pump/motor charges the hydraulic oil from the tank into the accumulator. When the accumulator reaches the maximal working pressure, the HHS makes the hydraulic oil overflow into the tank by the relief valve and the accumulator cannot recover the brake energy. The resistance produced by the pump/motor can decelerate the bus to a complete stop and the frictional brake should be applied only when the pump/motor cannot provide sufficient braking force. The deceleration of braking and the brake energy recovery are decided mainly by the torque coupler and the pump/motor. The brake energy recaptured can be reused to propel the bus during subsequent startup or acceleration. The key parameters of hydraulic hybrid bus used in this paper are listed in Table 1.

Table 1 The key parameters of hydraulic hybrid bus

\begin{tabular}{cc}
\hline Item & Value \\
\hline Bus total mass $(\mathrm{kg})$ & 15500 \\
Wheel radius $(\mathrm{m})$ & 0.53 \\
Ratio of the final drive & 4.875 \\
Gear ratio of torque coupler & $1.776,3.9468$ \\
Rated pump/motor displacement $(\mathrm{ml} / \mathrm{r})$ & 125 \\
Rated pump/motor speed $(\mathrm{r} / \mathrm{min})$ & 2600 \\
Accumulator volume $(\mathrm{L})$ & 100 \\
\hline
\end{tabular}

The pressurized tank can increase the inlet pressure of the pump/motor so that the maximal speed of the pump/motor can reach $2600 \mathrm{r} / \mathrm{min}$, thus the pump/motor can output higher power and the torque coupler has bigger gear ratio. Therefore, the HHS can output higher torque and the accumulator can recover more brake energy. Meanwhile, the bus has better brake and propulsion characteristics when the HHS provides the power exclusively.

\section{Dynamic programming algorithm}

The optimal strategy of brake energy recovery is to maximize the brake energy recovery of HHS. Based on brake energy recovery principle, DP algorithm can solve this global optimal control problem well. The key points of DP algorithm include the objective function and the constraint conditions of brake energy recovery.

\subsection{Objective function}

The recoverable brake energy of the accumulator can be expressed as

$$
E=\sum_{k=0}^{N-1} p(k) Q(k) \Delta t
$$

where $N$ is the total segment length of the driving cycle; $p(k)$ and $Q(k)$ are the pressure and the flow of the pump/motor at the $k$ brake time; $\Delta t$ is the time step.

Because the time step $\Delta t$ can be fixed, when the HHS can recover the maximal brake energy, (1) should meet the condition as

$$
P_{k}[x(k), k]=\max (p(k) Q(k))
$$

where $P_{k}[x(k), k]$ is the power of the pump/motor at the $k$ brake time.

Based on Boyle's law, the gas pressure and the volume of the accumulator meet the condition as

$$
p_{0} V_{0}^{n}=p(k)(V(k-1)-Q(k) \Delta t)^{n}=\mathrm{const}
$$

where $p_{0}$ and $V_{0}$ are the pre-charge pressure and volume of the accumulator, respectively; $V(k-1)$ is the gas volume of accumulator at the $k-1$ brake time; $n$ is the gas polytropic index.

Because the pressure of the pump/motor becomes higher as the increase of its flow, (3) implies these parameters $(p(k), Q(k))$ have consistent trends. Therefore, (1) has the maximal value when the flow of the pump/motor $Q(k)$ is largest. Based on brake energy recovery principle, the speed and the flow of the pump/motor can be expressed as

$$
\begin{gathered}
\omega(k)=\frac{i_{0}}{r} u(k) i_{2 g}(k) \\
Q(k)=\omega(k) D(k) \eta_{p v}(k)
\end{gathered}
$$

where $u(k)$ and $i_{2 g}(k)$ are the bus velocity and the gear ratio of the torque coupler, respectively; $\omega(k), D(k), \eta_{p v}(k)$ are the speed, the displacement and the volume efficiency of the pump/motor, respectively.

Referring to (4) and (5), the flow of the pump/motor can be expressed as

$$
Q(k)=\frac{i_{0}}{r} u(k) i_{2 g}(k) D(k) \eta_{p v}(k) .
$$

Therefore, the pump/motor flow $Q(k)$ is the objective function of brake energy recovery.

\subsection{Constraint conditions}

Equality (6) implies the objective function can be determined by the bus velocity $u(k)$, the gear ratio $i_{2 g}(k)$, the pump/motor displacement $D(k)$ and the volume efficiency $\eta_{p v}(k)$. When the drive path of the bus is fixed, the brake velocity $u(k)$ cannot be changed. The displacement and the speed of the pump/motor can determine the pressure of the pump/motor. The pressure, the flow and the speed of the pump/motor can determine the mechanical efficiency and the volume efficiency of the pump/motor. Therefore, 
the displacement of the pump/motor and the gear ratio of torque coupler are the constraint variables of brake energy recovery.

Because the output torque of the HHS cannot exceed the required torque of the bus and the displacement of the pump/motor cannot exceed its rated value, the output torque of the HHS and the displacement of the pump/motor must meet the conditions as

$$
\begin{gathered}
T_{p}(k)=\frac{p(k) D(k) i_{2 g}(k)}{\eta_{p m}(k) \eta_{2 g}(k)} \leqslant T_{r}(k) \\
0 \leqslant D(k) \leqslant D_{\max }
\end{gathered}
$$

where $T_{p}(k)$ is the output torque of the HHS; $\eta_{2 g}(k)$ is the working efficiency of the torque coupler; $T_{r}(k)$ is the required torque of the bus and defined between the final drive and the torque coupler; $D_{\max }$ is the rated value of the pump/motor.

Equations (7) and (8) are the constraint conditions of the displacement of the pump/motor. When the bus velocity is more than $27 \mathrm{~km} / \mathrm{h}$, the gear ratio of the torque coupler must be 1.776 because the pump/motor speed cannot exceed its rated value, Therefore, the constraint conditions of the gear ratio can be expressed as

$$
\left\{\begin{aligned}
i_{2 g}(k) & =1.776,3.9468, & & \text { for } u(k) \leqslant 27 \mathrm{~km} / \mathrm{h} \\
i_{2 g}(k) & =1.776, & & \text { for } u(k)>27 \mathrm{~km} / \mathrm{h} .
\end{aligned}\right.
$$

Referring to (7), (8) and (9), the constraint conditions of the objective function can be expressed as

$$
\begin{cases}\frac{p(k) D(k) i_{2 g}(k)}{\eta_{p m}(k) \eta_{2 g}(k)} \leqslant T_{r}(k) & \\ 0 \leqslant D(k) \leqslant D_{\max } & \\ i_{2 g}(k)=1.776,3.9468, & \text { for } u(k) \leqslant 27 \mathrm{~km} / \mathrm{h} \\ i_{2 g}(k)=1.776, & \text { for } u(k)>27 \mathrm{~km} / \mathrm{h} .\end{cases}
$$

\section{Implementable strategy}

The DP algorithm of brake energy recovery should be simulated for getting its implementable strategy. The drive path of the bus is Chinese typical urban bus cycle (CTUBC) and shown in Fig. 2, where, the line "*" is the maximal brake power cycle.

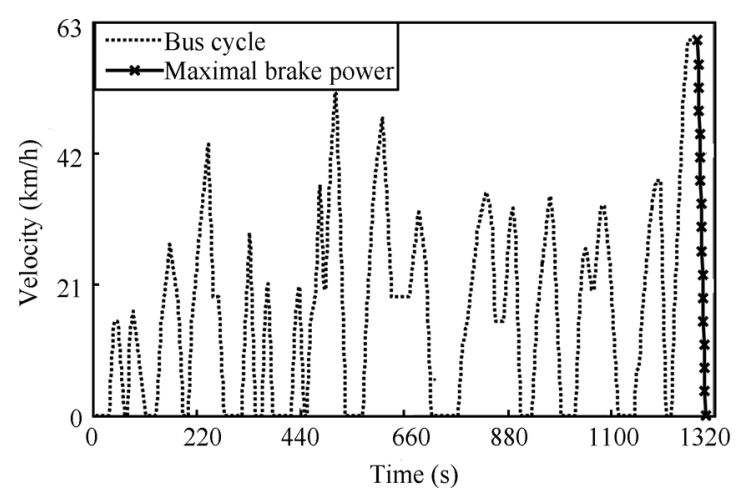

Fig. 2 Chinese typical urban bus cycle

The constraint variables of the DP algorithm are the displacement of the pump/motor and the gear ratio of the torque coupler. The analysis process considers only the maximal brake power cycle. The minimal pressure and the maximal pressure of the accumulator are 11 and $31.5 \mathrm{MPa}$, respectively. The brake energy recovery can be regarded as an adiabatic process because every brake process of the CTUBC takes less than one minute. So the polytropic index $n$ is 1.4 .

The brake energy recovery efficiency of the accumulator can be defined as

$$
\eta_{a}=\frac{E}{0.5 m u^{2}}
$$

where $m$ is the total mass of the bus.

And the unrecoverable brake energy percentage can be expressed as

$$
\eta_{b}=\frac{i_{0}}{0.5 m u \eta_{0} r}\left(T_{r}-\frac{p D i_{2 g}}{\eta_{p m} \eta_{2 g}}\right)
$$

where $\eta_{0}$ is the working efficiency of the final drive.

Thus, the total brake energy loss percentage of the roll resistance, the wind resistance, the final drive and the torque coupler can be expressed as

$$
\eta_{r}=1-\frac{\eta_{a}}{\eta_{p}}-\eta_{b}
$$

where $\eta_{p}$ is the total efficiency of the pump/motor.

\subsection{Torque coupler shifting schedule}

\subsubsection{Results analyses}

The result of the shifting schedule of the torque coupler is shown in Fig. 3.

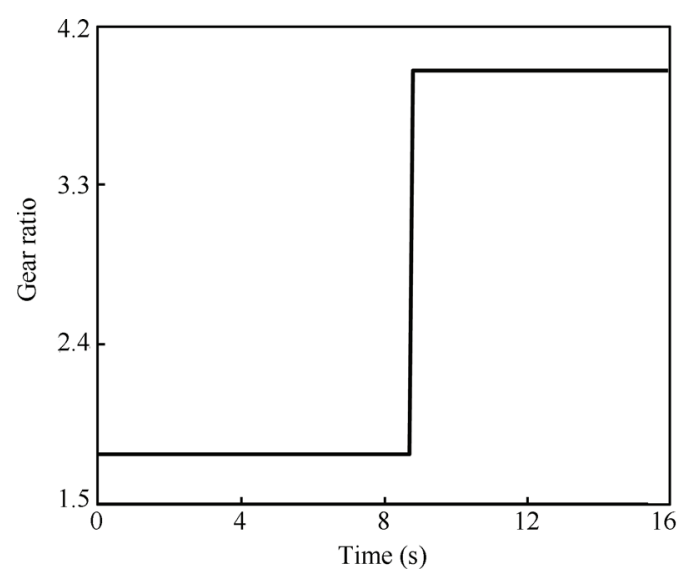

Fig. 3 Shifting schedule of torque coupler

As shown in Fig. 3, the torque coupler works as a gear with big gear ratio when the bus velocity is small. When the bus velocity exceeds $27 \mathrm{~km} / \mathrm{h}$, the torque coupler works as a gear with small gear ratio. Therefore, the shifting schedule of the torque coupler can be concluded as follows:

1) When the bus velocity $u \leqslant 27 \mathrm{~km} / \mathrm{h}$, the torque coupler works with the gear ratio $i_{2 g}=3.9468$;

2) When the bus velocity $u>27 \mathrm{~km} / \mathrm{h}$, the torque coupler works with the gear ratio $i_{2 g}=1.776$.

\subsubsection{Discuss and validation}

Based on brake energy recovery principle, the torque coupler should have two shifting schedules available: The first 
shifting schedule is shown in Section 4.1.1. The second shifting schedule is that the torque coupler keeps working at the small gear ratio overall brake process. The output torques of the HHS in the two shifting schedules are shown in Fig. 4.

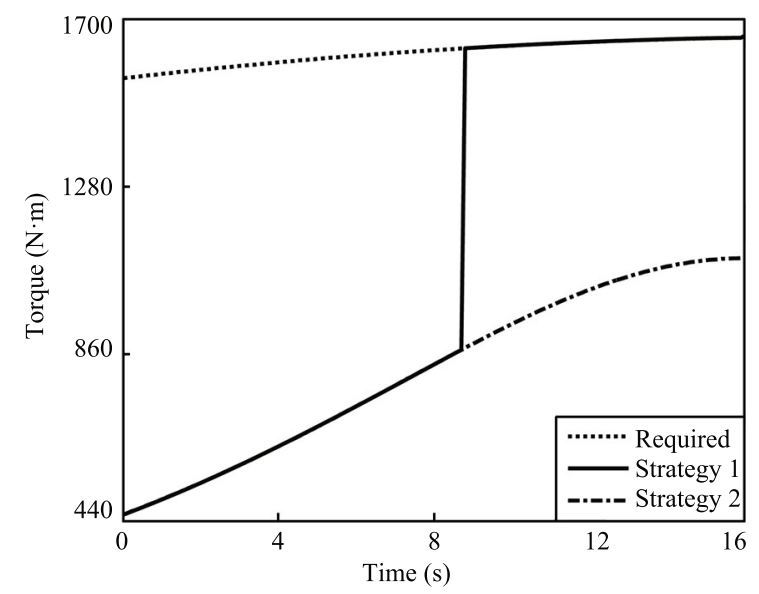

Fig. 4 Output torque trajectories of two shifting schedules

As shown in Fig. 4, when the bus velocity is more than $27 \mathrm{~km} / \mathrm{h}$, the HHS output equal torques in two shifting schedules because the torque coupler keeps the small gear ratio and the accumulator has equal initial pressures. And the output torque cannot meet the required torque of the bus. When the bus velocity is less than $27 \mathrm{~km} / \mathrm{h}$, the torque coupler keeps the big gear ratio in the first shifting schedule. And the output torque can meet the required torque of the bus. However, the torque coupler keeps the small gear ratio in the second shifting schedule and the HHS cannot meet the required torque of the bus.

Different brake energy consumptions in the two shifting schedules are listed in Table 2 based on simulation results. The initial kinetic energy of the bus is $2152.8 \mathrm{~kJ}$ when it is driven in the maximal brake power cycle in Fig. 2.

Table 2 Different brake energy distribution percentages in the two shifting schedules

\begin{tabular}{ccccc}
\hline Strategy & $\eta_{r}(\%)$ & $\eta_{b}(\%)$ & $\eta_{p}(\%)$ & $\eta_{a}(\%)$ \\
\hline Strategy 1 & 12.12 & 43.61 & 87.6 & 38.8 \\
Strategy 2 & 11.11 & 51.28 & 86.4 & 32.5 \\
\hline
\end{tabular}

As shown in Table 2, most of the brake energy can be wasted in the frictional brake system. However, the accumulator can recover more brake energy in the first shifting schedule than that in the second one because the HHS can provide bigger braking torque in the first shifting schedule when the bus velocity is less than $27 \mathrm{~km} / \mathrm{h}$. Moreover, the bus has shorter braking distance in the first shifting schedule if the HHS brakes the bus exclusively.

\subsection{Pump/motor displacement strategy}

Based on brake energy recovery principle, the implementable strategy can be established as follows: When the bus velocity is more than $27 \mathrm{~km} / \mathrm{h}$, the pump/motor works with the maximal displacement and the torque coupler works as a gear with small gear ratio. When the bus speed is no more than $27 \mathrm{~km} / \mathrm{h}$, the displacement of the pump/motor can vary for meeting the required torque of the bus and the torque coupler works with a gear with big gear ratio.

The simulation results of the pump/motor displacement are compared in Fig. 5 between the DP algorithm and the implementable strategy. The displacement of the pump/motor and the output torque of the HHS in the DP algorithm are shown by the solid line. And the displacement of the pump/motor and the output torque of the HHS in the implementable strategy are shown by the dash line. The required torque of the bus is shown in the dash dot line of Fig. 5 (b).

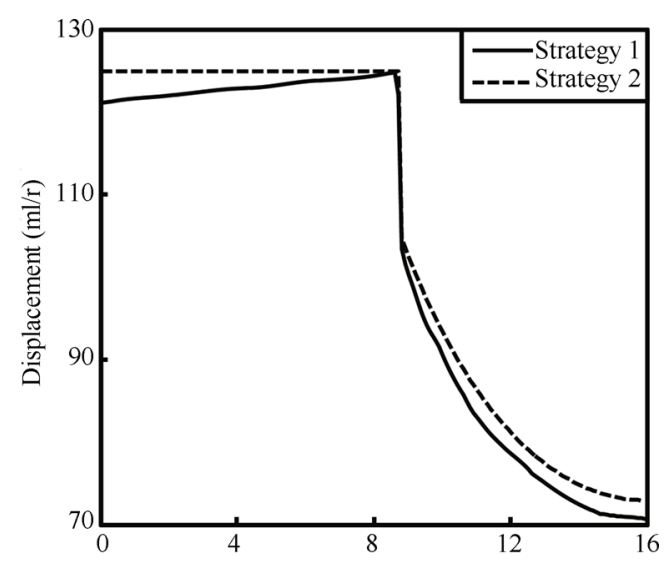

(a) Time (s)

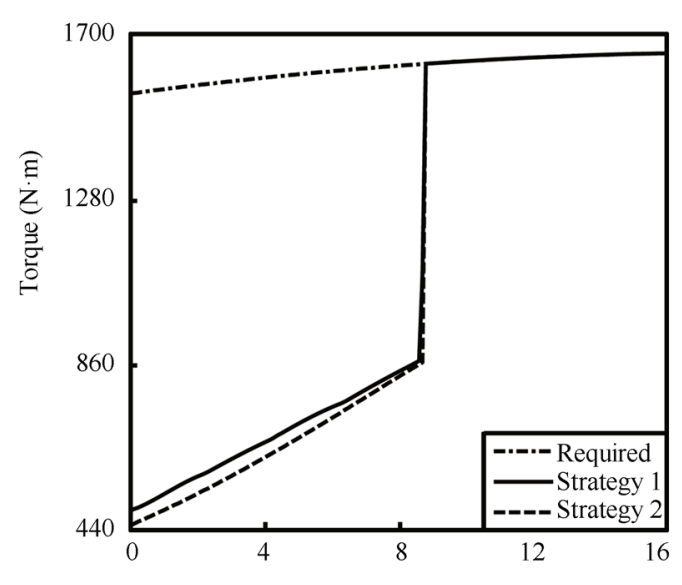

(b) Time (s)

Fig. 5 Displacement trajectories of the pump/motor

As shown in Fig. 5(a), the displacement of the pump/motor increases gradually to $125 \mathrm{ml} / \mathrm{r}$ in the DP algorithm and keeps the value at $125 \mathrm{ml} / \mathrm{r}$ in the implementable strategy when the bus velocity is more than $27 \mathrm{~km} / \mathrm{h}$. The torque coupler works as a gear with small gear ratio. Fig. 5 (b) shows the output torque of the HHS in the DP algorithm is bigger than that in the implementable strategy at the same time. Moreover, the output torque of the HHS in the two strategies cannot meet the required torque of the bus.

When the bus velocity is no more than $27 \mathrm{~km} / \mathrm{h}$, the torque coupler works as a gear with big gear ratio. Fig. 5 (b) 
shows the output torques of the HHS in the two strategies are equal and can meet the required torque of the bus. As the pressure of the accumulator becomes high, the displacement of the pump/motor in the two strategies decreases gradually. Moreover, the displacement of the pump/motor in the DP algorithm is smaller than that in the implementable strategy at the same time.

In order to compare the brake energy recovery efficiency, different brake energy consumption percentages in the two strategies are listed in Table 3.

Table 3 Different brake energy consumption percentages in the two strategies

\begin{tabular}{ccccc}
\hline Strategy & $\eta_{r}(\%)$ & $\eta_{b}(\%)$ & $\eta_{p}(\%)$ & $\eta_{a}(\%)$ \\
\hline DP & 12.12 & 43.61 & 87.6 & 38.8 \\
Implementable & 10.48 & 45.7 & 85.8 & 37.6 \\
\hline
\end{tabular}

As shown in Table 3, the loss of the brake energy and the unrecoverable brake energy have almost the same percentages between the DP algorithm and the implementable strategy. Therefore, the accumulator has almost equal efficiency of the brake energy recovery in the two strategies.

\section{Results and discussion}

\subsection{Brake torque analysis}

The models and the propulsion strategy of the parallel hydraulic hybrid bus are available in [8]. The HHS output torque of the implementable strategy in the CTUBC is shown in Fig. 6(b). Fig. 6 (a) shows the pressure of the accumulator trajectories, which is helpful for explaining the output torque of the HHS. In order to acquire sufficient hydraulic energy for optimizing the engine fuel economy, the engine charges the accumulator for the full pressure before the bus launching. The horizontal dash line represents the bus velocity is $27 \mathrm{~km} / \mathrm{h}$.

As shown in Fig. 6 (a), the accumulator has the minimal pressure when most brake cycle ends, which implies the recoverable brake energy has been utilized fully. If the initial brake velocity is very high, the accumulator can reach full pressure when the brake process ends (Fig. 6 (a) zone A); if the initial brake velocity is low, the accumulator cannot reach full pressure when the brake process ends (Fig. 6 (a) zone B). Therefore, the engine should charge the accumulator for full pressure before the bus launching. Observed from intersection point of the horizontal dash line $27 \mathrm{~km} / \mathrm{h}$ and the CTUBC, the HHS can propel the bus exclusively from stand-still to $27 \mathrm{~km} / \mathrm{h}$ in every bus launching.

As shown in Fig. 6(b), the HHS can provide most of brake torque. When the required torque is small, the HHS can brake the bus exclusively (Fig. 6 (b) zone C) and recover all brake energy. When a high torque is required, the pump/motor works with the maximal displacement if the HHS cannot meet the required torque exclusively (Fig. 6 (b) zone $\mathrm{D})$. When the brake velocity is less than $27 \mathrm{~km} / \mathrm{h}$, the HHP can meet the required torque (Fig. 6 (b) zone D) and recover all brake energy.

\subsection{Brake energy recovery efficiency}

The recovery efficiency of the brake energy needs to be analyzed for comparing the DP algorithm and the implementable strategy in the CTUBC. the simulation results show the total brake energy in the CTUBC is $12656 \mathrm{~kJ}$, different brake energy consumptions percentages are calculated and listed in Table 4.

Table 4 Brake energy consumption percentages of the two strategies in the CTUBC

\begin{tabular}{ccccc}
\hline Strategy & $\eta_{r}(\%)$ & $\eta_{b}(\%)$ & $\eta_{p}(\%)$ & $\eta_{a}(\%)$ \\
\hline DP & 19.36 & 14.15 & 89.74 & 59.67 \\
Implementable & 18.4 & 15.88 & 88.32 & 58.04 \\
\hline
\end{tabular}

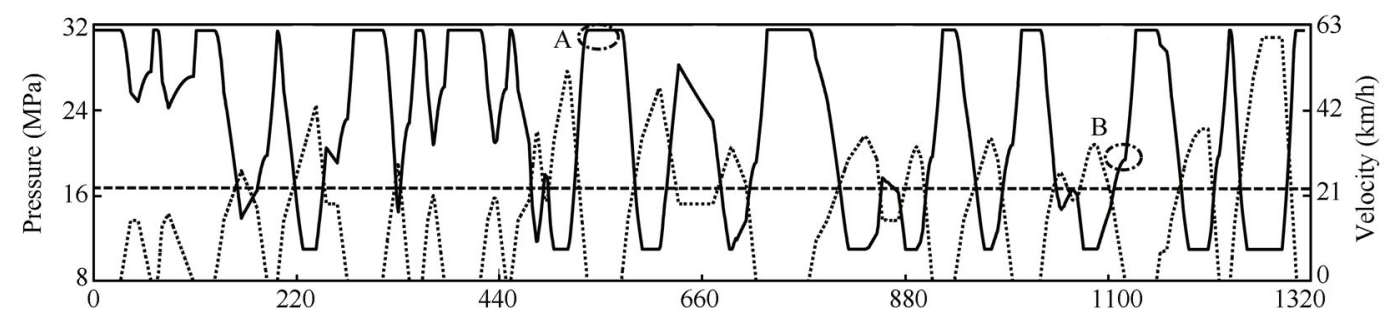

(a) Pressure (MPa)

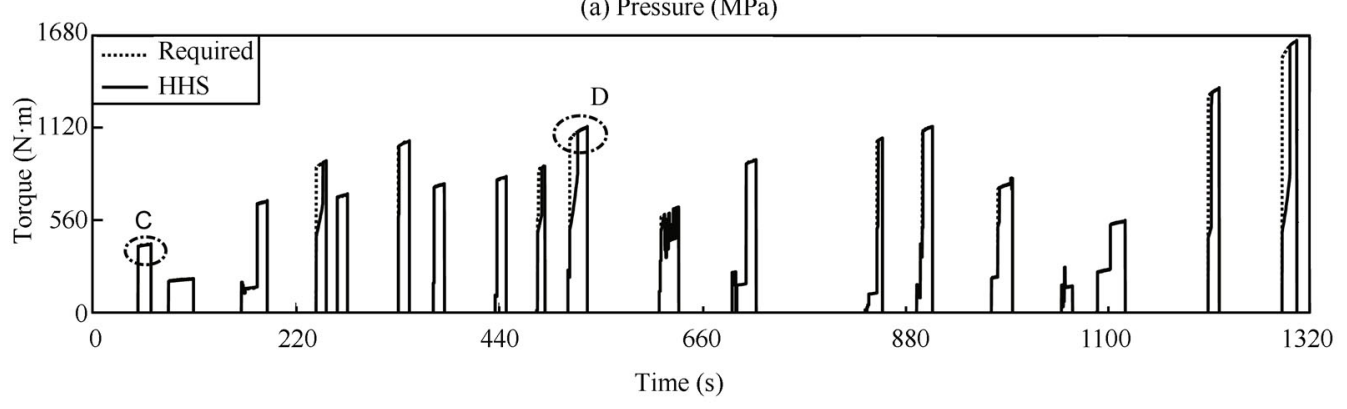

(b) Torque $(\mathrm{N} \cdot \mathrm{m})$

Fig. 6 Output torque trajectories of the HHS 
As shown in Table 4, the unrecoverable brake energy percentage has decreased greatly in the CTUBC compared to the maximal brake power cycle. The unrecoverable brake energy percentage is highest because the required torque of the bus is biggest in the maximal brake power cycle. And the unrecoverable brake energy percentage decreased gradually in the other brake cycle of the CTUBC. The accumulator can recover all brake energy in many brake cycles. Therefore, the unrecoverable brake energy percentage has decreased greatly in the CTUBC compared to the maximal brake power cycle. The recovery efficiency of the brake energy increases as the percentage decrease of the unrecoverable brake energy. Therefore, the brake energy recovery efficiency of the accumulator can reach almost $60 \%$. Compared to the brake energy recovery efficiency of the accumulator, there is only a little difference in the two strategies. Therefore, the implementable strategy can reach almost equal brake energy recovery efficiency of the DP algorithm.

\section{Road tests}

A parallel hydraulic hybrid bus was used in this work and its key parameters are shown in Table 1 . When the HHS stops working, the hydraulic hybrid bus becomes a conventional bus. Fig. 7 shows the picture the of the test bus and the HHS. If the working pressure is lower than $11 \mathrm{MPa}$ or higher than $31.5 \mathrm{MPa}$, the accumulator stops releasing or recovering brake energy, respectively. The pressure and the flow of the accumulator are measured by the corresponding sensors, respectively. The fuel consumption of the engine is measured by the fuel consumption instrument. The driving path is the CTUBC. The test distance of TUBC is $5898 \mathrm{~m}$.

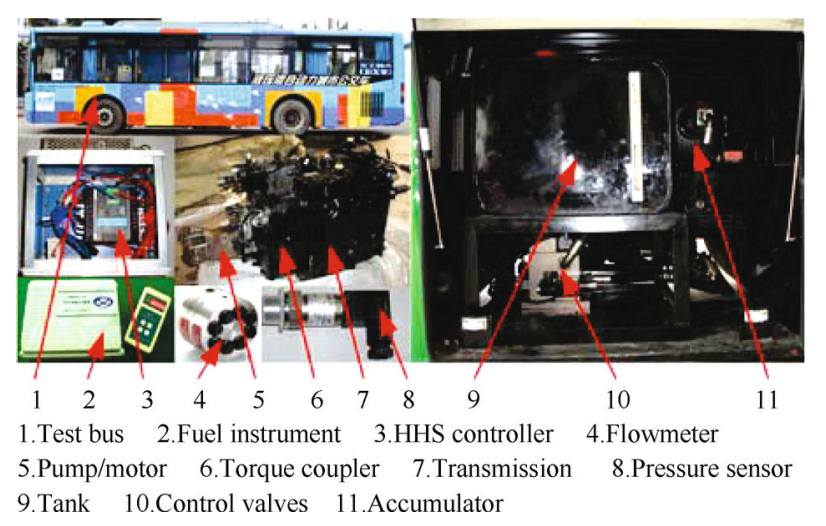

Fig. 7 The picture of test bus and the HHS

The accurate measurement of the total brake energy loss is very difficult in the road tests because the roll resistance, the wind resistance, and the energy loss of the final drive and the torque coupler can not be determined accurately. However, the pressure and the flow of the accumulator can be measured accurately by the pressure sensor and the flowmeter, respectively. So the recoverable brake energy of the accumulator can be acquired as

$$
E=\int_{0}^{t_{f}} p Q \mathrm{~d} t
$$

The recoverable brake energy of the accumulator in the CTUBC is shown in Fig. 8. The recoverable brake energy of the accumulator increases gradually as the bus drives forward. Based on calculation from function (14), the recoverable brake energy of the accumulator can reach $7076 \mathrm{~kJ}$ when all braking process ends. Thus the brake energy recovery efficiency of the accumulator is $55.91 \%$ by the calculation from function (1). The result error of the brake energy recovery is $2.13 \%$ as given in Table 4 showing comparison between the simulation and the test. And the main reasons of the error are the internal leakage and heat loss. However, there exists a good agreement of the simulation results compared with the test data.

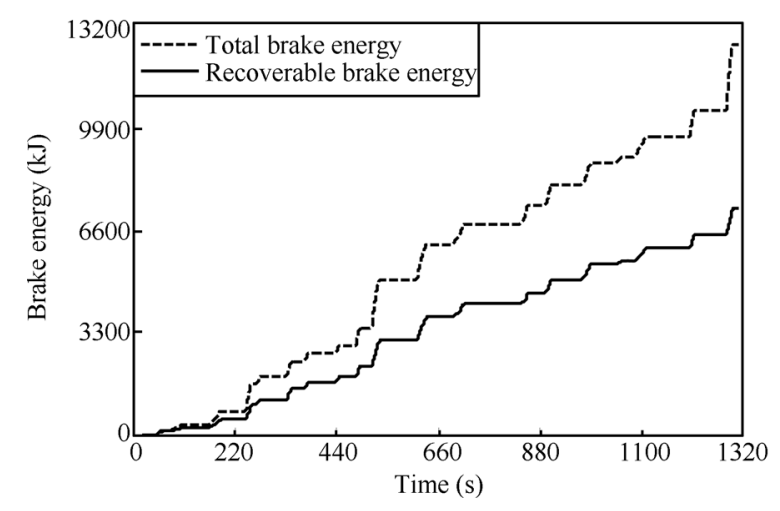

Fig. 8 Recoverable brake energy trajectories

The fuel consumption of the engine can be measured accurately by the fuel instrument in the road tests. And the trajectories of the convention bus and the hydraulic hybrid bus are shown in Fig. 9. The fuel consumption of the engine increases gradually as the bus drives forward. Based on calculation from Fig. 9 the fuel consumption of the hydraulic hybrid bus and the conventional bus are 25.73 and $33.24 \mathrm{~L}$ in the $100 \mathrm{~km}$, respectively. Compared with the conventional bus, the fuel economy of the hydraulic hybrid bus improves by $22.6 \%$. Therefore, the fuel economy of the hydraulic hybrid bus improves greatly because of the implementable strategy of the brake energy recovery.

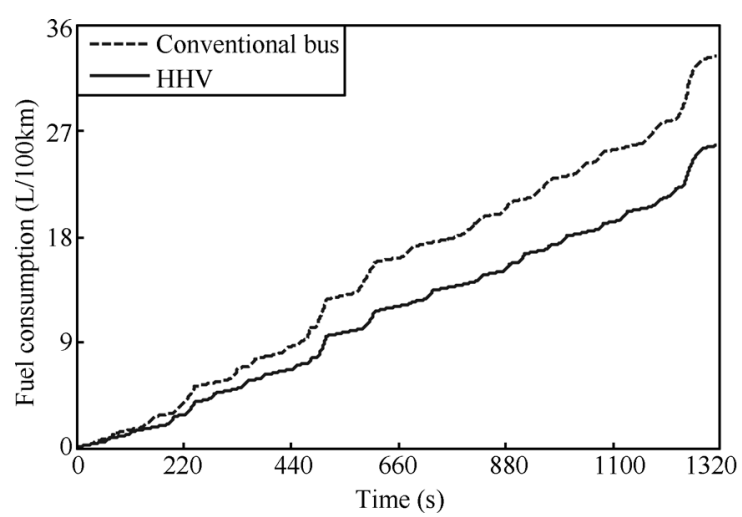

Fig. 9 The fuel consumption trajectories of the engine

\section{$7 \quad$ Summary and conclusions}

This study introduced the brake energy recovery principle of the HHS, and then established a DP algorithm of brake energy recovery. The flow of the pump/motor was determined as the objective function and the constraint con- 
ditions are the gear ratio of torque coupler and the displacement of the pump/motor by analyzing the recovery process of the brake energy.

Based on simulation results analysis of the DP algorithm in the maximal brake power cycle of the CTUBC, the implementable strategy of brake energy recovery has been proposed: When the bus velocity is more than $27 \mathrm{~km} / \mathrm{h}$, the pump/motor works with the maximal displacement and the torque coupler works as a gear with small gear ratio. When the bus velocity is no more than $27 \mathrm{~km} / \mathrm{h}$, the pump $/$ motor displacement can vary for meeting the required torque of the bus and the torque coupler works as a gear with big gear ratio. These results are validated by comparing the output torques and the brake energy distributions in the two shifting schedules.

The simulation results indicated the implementable strategy of the brake energy recovery can make full use of braking characteristics and most of the braking torque can be provided exclusively by the pump/motor in the CTUBC. Moreover, the HHS can propel the bus exclusively from stand-still to $27 \mathrm{~km} / \mathrm{h}$ in every bus launching, which implied the engine do not need to work in the low fuel economy zone. The brake energy recovery efficiency of the accumulator can reach almost $60 \%$ which shows that there is only a little difference between the implementable strategy and the DP algorithm. Therefore, the implementable strategy is very effective in improving the efficiency of brake energy recovery in the hydraulic hybrid bus. Finally, the road tests validated the simulation results of the brake energy recovery efficiency in the implementable strategy. And the fuel economy of the hydraulic hybrid bus can reach $22.6 \%$ as compared to the conventional bus.

\section{Acknowledgments}

The authors gratefully acknowledge the support of the Institute of Automotive Engineering at the School of Mechanical Engineering, Shanghai Jiao Tong University, China.

\section{References}

[1] T. Liu, H. Q. Liu, J. H. Jiang. Factors influencing regenerative braking of parallel hydraulic hybrid vehicles. Journal of Jilin University, vol.40, no. 6, pp. 1473-1477, 2010. (in Chinese)
[2] R. S. Bonab, S. Rahman. Clean automotive technology: Hydraulic hybrid vehicles (HHVs). In Proceedings of Regional Conference on Automotive Research, Kuala Lumpur, Malaysia, pp. 12-15, 2011.

[3] K. E. Rydberg. Energy efficient hydraulic hybrid drives. In Proceedings of the 11th Scandinavian International Conference on Fluid Power, Linköping, Sweden, pp. 1-14, 2009.

[4] Q. Y. Zhang, S. Q. Chang. Braking energy recycling for hydraulically-driven hybrid-powered vehicles. Chinese Journal of Construction Machinery, vol.6, no. 3, pp. 293-298, 2008.

[5] C. Chen, T. Vu. Regenerative braking study for a hydraulic hybrid vehicle. In Proceedings of the 9th World Congress on Intelligent Control and Automation, IEEE, Taipei, China, pp. 413-418, 2011.

[6] B. Wu, C. C. Lin, Z. Filip, H. Peng, D. Assanis. Optimal power management for a hydraulic hybrid delivery truck. Vehicle System Dynamics, vol. 42, no. 1-2, pp. 23-40, 2004.

[7] H. Sun, J. H. Jiang, X. Wang, Torque control strategy for a parallel hydraulic hybrid vehicle. Journal of Terramechanics, vol. 46, no. 6, pp. 259-265, 2009.

[8] Y. C. Yan, G. Q. Liu, J. Chen. Integrated modeling and optimization of a parallel hydraulic hybrid bus. International Journal of Automotive Technology, vol.11, no. 1, pp.97104, 2010.

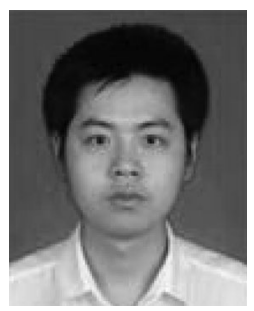

Zhong-Liang Zhang received his B. Eng. degree from Wuhan University of Technology (WHUT), China in 2005, and his M. Eng. degree from Huazhong University of Science and Technology (HUST), China in 2007. He is currently a Ph. D. candidate at the Institute of Body Manufacturing Technology Center of Shanghai Jiao Tong University, China.

His research interests include hybrid powertrain technology, especially in the field of parallel hydraulic hybrid bus.

E-mail: zzl_hust@163.com (Corresponding author)

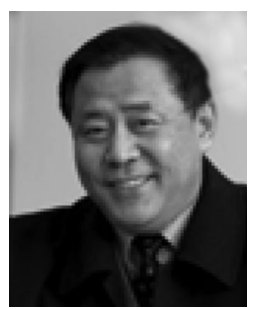

Jie Chen received his $\mathrm{Ph}$. D. degree from Jilin University, China in 1997. Currently, he is a professor in the Institute of Body Manufacturing Technology Center of Shanghai Jiao Tong University, China.

His research interests include hydraulic hybrid vehicle, electronics automobiles, and special vehicle design.

E-mail: ChenJie9067@163.com 